Francisco Garcia-Olmedo

Gabriel Salcedo

Cipriano Aragoncillo

Rosa Sánchez-Monge

Carmen Collada

Luis Gómez

Programa de Biotecnologia

Agroforestal, Universidad Politécnica de Madrid

\section{Two-dimensional electrophoresis as a tool for structural and genetic studies of seed proteins from Poaceae and Fagaceae}

\begin{abstract}
The application of two-dimensional electrophoretic procedures to structural and genetic studies of seed proteins from Poaceae (including the cultivated cereals) and Fagaceae is described. The following related problems have been considered: covalent and non-covalent association of protein subunits in multiple oligomeric structures; chromosomal locations of genes encoding seed proteins; quantitation of gene products in relation to gene expression and regulation; purification of protein components to study their homology relationships and in vitro activities; evolutionary and phylogenetic relationships; identification of genetic stocks. Isoelectric focusing, pore-gradient electrophoresis, electrophoresis at different $\mathrm{pH}$ 's, are among the separation procedures used in the first dimension, whereas sodium dodecyl sulfate-polyacrylamide gel electrophoresis and starch-gel electrophoresis at acid $\mathrm{pH}$ have been the preferred second-dimensional methods. Dissociating conditions (sodium dodecyl sulfate, Nonidet P-40, or urea) and reducing conditions (2-mercaptoethanol) have been used when required.
\end{abstract}

\section{Introduction}

The resolution of complex protein mixtures is a problem that often confronts the biologist, whether his interest is in the organelle or in the organism, in structure or in function, in physiology or in genetics and development. Electrophoresis has for a long time been one of the more powerful tools among the combination of techniques traditionally used to solve this problem. However, not until the landmark development of two-dimensional (2-D) methods, such as those of Wrigley [1] and O'Farrell [2], has the problem been solved with the versatility and resolution required for many of the applications. These methods have been particularly useful to the geneticist, who is basically interested in variation, such as that of the products from the different alleles at one locus or from the different members of a multigene family, which means that he has to resolve mixtures of proteins that are closely related from a structural point of view. Quantitation and succinct characterization of the resolved proteins are often additional requirements in genetic studies. Quantitative and preparative 2-D methods in combination with recent developments in instrumentation, both in image-processing and microanalytical equipment, have significantly contributed to meet these requirements.

The greater genetic redundancy of plant genomes, which are often (allo)polyploid, as compared with that of other types of organisms, is probably responsible for the extensive use of a great variety of 2-D techniques by plant geneticists. In the course of our studies on the genetic control of seed protein carried out over the past fifteen years [3-15], we have applied these methods to separate, quantitate, and purify a wide range of proteins. The purpose of this contribution is to summarize and illustrate these procedures, with special emphasis in the more recent developments concerning structural and genetic

\footnotetext{
Abbreviations: CM-proteins, proteins soluble in chloroform/methanol mixtures; lEF, isoelectric focusing: LMWP, low molecular weight prolamins; 2-ME, 2-mercaptothanol; NP-40, Nonidet P-40; PAGE, polyacrylamide gel electrophoresis; SDS, sodium dodecyl sulfate; SGE, starch gel electrophoresis; 2-D, two-dimensional
}

studies of seed proteins from the Poaceae, including the main cereal crops, and the Fagaceae. These two taxa can be considered as representative of herbaceous annual crops and long-lived woody plants.

\section{Materials and methods}

\subsection{Biological material}

Individual seeds or flours of the following species were analysed in this study: Triticum aestivum, Triticum turgidum, Triticum tauschii, Hordeum vulgare, Hordeum spontaneum, Secale cereale, Castanea sativa, Castanea crenata and Quercus suber. The chromosomal location of genes for different proteins from cereal endosperms was carried out by analysis of the nulli-tetrasomic and ditelosomic lines from $T$. aestivum, cv. Chinese Spring and of the Chinese Spring wheat/ Imperial rye disomic addition lines (E. R. Sears, Columbia, MO, USA).

\subsection{Two-dimensional electrophoretic methods}

The protein preparations indicated in each case (crude extracts, solubility or gel-filtration fractions, etc.) were subjected to one or more of the following 2-D separation methods.

\subsubsection{Isoelectric focusing (IEF) and starch gel electrophoresis (SGE)}

For first-dimensional IEF we used: $2 \times 140 \mathrm{~mm}$ gels; $5 \%$ polyacrylamide, $6 \mathrm{~m}$ urea; $\mathrm{pH} 3-10, \mathrm{pH} 4-9, \mathrm{pH} 5-8$ or $\mathrm{pH}$ 6-8 carrier ampholytes; $35 \mathrm{~V} / \mathrm{cm}$; focusing for $7 \mathrm{~h}$; sample application in $50 \mu \mathrm{L}$ of $9 \mathrm{M}$ urea at the acidic end. For seconddimensional SGE we used: $0.1 \mathrm{M}$ aluminum lactate buffer, $\mathrm{pH}$ $3.2,3 \mathrm{~m}$ urea; $12 \%$ starch; $18 \times 28 \times 0.1 \mathrm{~cm}$ gel slabs; $18 \mathrm{~V} /$ $\mathrm{cm}$; electrophoresis for $4 \mathrm{~h}$. Non-dissociating conditions in the first dimension were achieved by omitting $6 \mathrm{M}$ urea in the IEF gel. A modification of this method was introduced for the quantitation of the $T$. turgidum allelic variants $\mathrm{CM} 3$ and CM 3'; IEF was in $2 \times 60 \mathrm{~mm}$ gels, pH 7-9 carrier ampholytes, $45 \mathrm{~V} / \mathrm{cm}$; focusing for $6 \mathrm{~h}$; four electrofocused samples were 
inserted in a single $28 \times 18 \times 0.2 \mathrm{~cm}$ starch gel and run at $14 \mathrm{~V} /$ $\mathrm{cm}$ for $90 \mathrm{~min}$ (see Fig. 8).

\subsubsection{Gradient polyacrylamide gel electrophoresis (PAGE) and sodium dodecyl sulfate (SDS)-PAGE in absence of 2-mercaptoethanol (2-ME)}

The first-dimensional gradient PAGE was carried out in a discontinous buffer system under non-dissociating conditions. The buffer system of Ornstein and Davies was used [16,17] and the polyacrylamide gradient was $5-20 \%$. The gel dimensions were $15 \times 25 \times 0.2 \mathrm{~cm}$. Electrophoresis was at $20 \mathrm{~V} / \mathrm{cm}$ for $24 \mathrm{~h}$ at $4{ }^{\circ} \mathrm{C}$. The second-dimensional SDS-PAGE was carried out by the method of Laemmli [ 18$\}$ in $14 \times 25 \times 0.2 \mathrm{~cm}$ $15 \%$ separating polyacrylamide gels. Appropriate strips of non-dissociating gel were incubated in sample buffer with $3 \%$ SDS [18], 4h at room temperature, before insertion.

\subsubsection{SDS-PAGE without 2-ME and SDS-PAGE with 2-ME}

Both dimensions were performed according to Laemmli [ 18]. Strips from a first-dimensional gel were incubated in sample buffer with $3 \%$ SDS, $10 \% 2$-ME for $4 \mathrm{~h}$ at $40^{\circ} \mathrm{C}$, before they were applied to the second-dimensional gel. The separating $15 \%$ polyacrylamide gel was $14 \times 25 \times 0.2 \mathrm{~cm}$.

\subsubsection{Non-equilibrium IEF and SGE}

IEF was as in Section 2.2.1 except that the first-dimensional IEF was in preformed $\mathrm{pH}$ gradients $(0.5 \mathrm{~mA} /$ gel until reaching $470 \mathrm{~V})$ and the separation lasted $2-3 \mathrm{~h}$.

\subsubsection{PAGE $\times$ SGE}

The fractionation of low molecular weight prolamins (LMWP) was carried out in the following system (see Fig. 6): first dimension in $0.066 \mathrm{M}$ Tris-0.19 $\mathrm{M}$ glycine buffer, $\mathrm{pH} 9.0$, $3 \mathrm{M}$ urea in $2 \times 70 \mathrm{~mm} 10 \%$ polyacrylamide gels. Sample was applied in $25 \mu \mathrm{L}$ of $9 \mathrm{M}$ urea and run at $50 \mathrm{~V} / \mathrm{cm}$ for $2.5 \mathrm{~h}$. The second dimension was as in Section 2.2.1 except that SGE was at $12 \mathrm{~V} / \mathrm{cm}$ for $15 \mathrm{~h}$.

\subsubsection{SGE (pH 5.2) $\times$ SGE (pH 3.2)}

The separation and quantitation of wheat purothionin variants (Fig. 7) were performed in a $0.02 \mathrm{M}$ sodium acetate buffer, pH 5.2, in $18 \times 28 \times 0.2 \mathrm{~cm} 12 \%$ starch gels, at $10 \mathrm{~V} /$ $\mathrm{cm}$ for $2 \mathrm{~h}$. Appropriate strips of this gel were excised and inserted for a second-dimensional separation in $0.015 \mathrm{M}$ aluminum lactate buffer, $3 \mathrm{M}$ urea, $\mathrm{pH} 3.2$, in $18 \times 28 \times 0.2 \mathrm{~cm}$ $12 \%$ starch gels, and separated at $10 \mathrm{~V} / \mathrm{cm}$ for $2-3 \mathrm{~h}$.

\subsubsection{IEF $\times$ SDS-PAGE with or without 2-ME}

The first dimension was as described in Section 2.2 .1 with $\mathrm{pH}$ 3.5-10 carrier ampholytes (Ampholine). The second dimension was performed according to Laemmli [ 18]. The IEF gels were incubated prior to application to the second dimension as described in Sections 2.2.2 and 2.2.3. For the identification of C. sativa $\times$ C. crenata hybrids a modification of this method was used. The IEF was carried out in the presence of $2 \%$ Non- idet P-40 (NP-40). Samples were applied in $30 \mu \mathrm{L}$ of $9 \mathrm{M}$ urea, $2 \% \mathrm{NP}-40,10 \% 2-\mathrm{ME}$. Focusing was at $35 \mathrm{~V} / \mathrm{cm}$ for $16 \mathrm{~h}$.

\subsubsection{Staining and densitometry}

Staining of 2-D gels was carried out with $0.05 \%$ Nigrosine when SGE was used in the second dimension [19], or Coomassie Brilliant Blue G-250 when PAGE was used $[20\rceil$. Quantitation of protein components in 2-D maps was performed using standard densitometric methods $[5,6]$.

\section{Results and discussion}

We have selected a number of representative studies with the aim of illustrating both the range of problems investigated and the variety of 2-D electrophoretic techniques used. The following closely related aspects of this work will be successively considered: (i) determination of different types of protein association in the reserve tissues, (ii) study of chromosomal location and expression of genes encoding seed proteins, and (iii) investigation of phylogenetic and evolutionary relationships.

\subsection{Structural studies}

\subsubsection{Subunit structure of oligomeric $\alpha$-amylase inhibitors from barley}

Monomeric, dimeric and tetrameric inhibitors of heterologous $\alpha$-amylases have been described in cereal endosperm $[21,22]$. The first two classes of inhibitors had been extensively characterized and found to form a homology group together with trypsin inhibitors [22], whereas less information was available concerning the tetrameric inhibitors. It had been presumed that the subunits of the latter were in the same homology group as those of the other inhibitors, but direct evidence was lacking. To confirm such hypothesis, a crude preparation of the barley tetrameric inhibitor was obtained by gel filtration of a protein fraction precipitated with $50 \% \mathrm{am}$ monium sulfate from a $0.15 \mathrm{M} \mathrm{NaCl}$ extract. This preparation was analyzed by combined IEF ( $\mathrm{pH} 5-8$ ) x SGE (pH 3.2), using both dissociating ( $6 \mathrm{M}$ urea) and non-dissociating (without urea) conditions in the first dimension (Fig. 1). Three prominent components, with identical mobilities to the previously described proteins $\mathrm{CMa}, \mathrm{CMb}$ and $\mathrm{CMd}|23|$, were observed in the 2-D map obtained under dissociating conditions (Fig. $1 B$ ), indicating that these proteins were indeed the subunits of the tetrameric inhibitor. These components comigrated in the first-dimensional gel when the separation was carried out in the absence of urea, giving the 2-D pattern expected of oligomers containing these subunits in different combinations (Fig. 1C). A similar association pattern was reconstructed by subjecting a mixture of the three purified proteins to the same 2-D separation (Fig. ID). Proteins $\mathrm{CMa}, \mathrm{CMb}$ and $\mathrm{CMd}$ had been previously shown to be homologous to the other inhibitors, although only CMa had been found to be inhibitory by itself [24]. Binary and tertiary mixtures of the subunits showed markedly enhanced activity in comparison with the pure subunits, giving further support to the interpretation of the 2-D maps [25]. A similar approach has permitted the elucidation of the subunit structure of the wheat tetrameric inhibitors ([14] and L. Gomez et al., unpublished). 

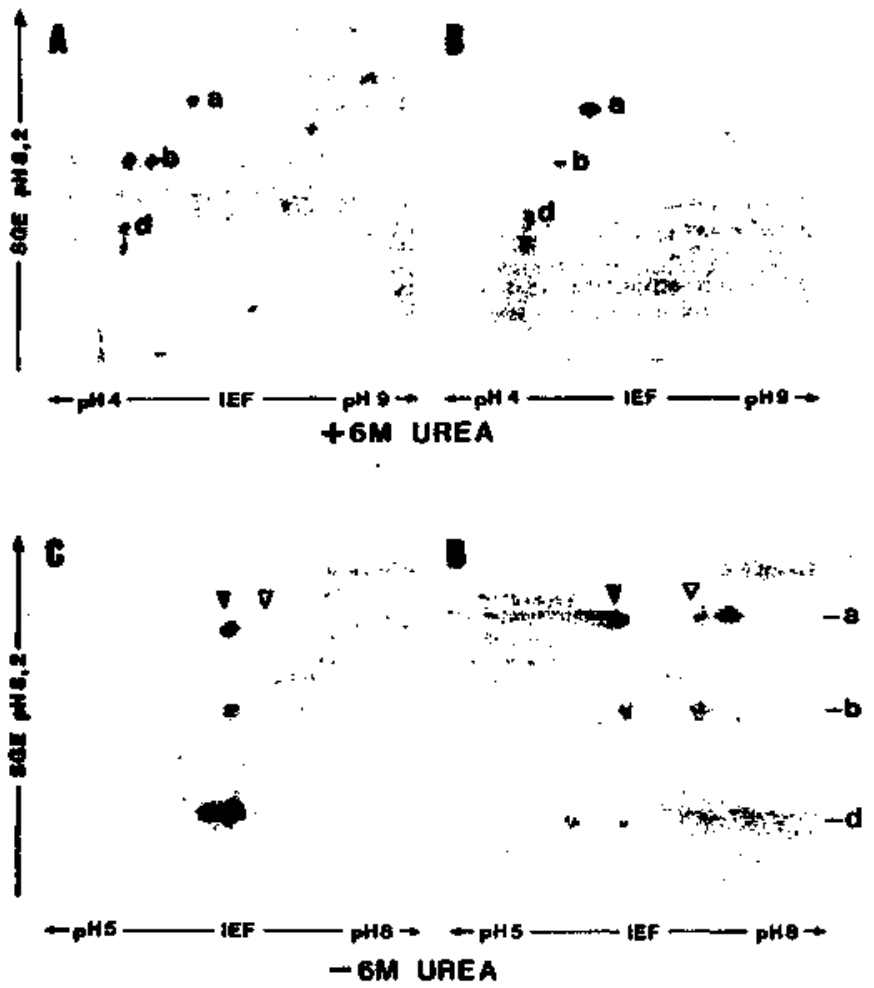

Figure 1. 2-D separation by combined JEF (pH 4-9 or $\mathrm{pH} 5-8) \times \mathrm{SGE}(\mathrm{pH}$ 3.2). (A) Total extract. (B), (C) Gel filtration fraction corresponding to tetrameric inhibitors. (D) Mixture of the purified proteins $\mathrm{CMa}$. $\mathrm{CMb}$ and CMd. (A). (B) Dissociating conditions ( $6 \mathrm{M}$ urea) were used in the first dimension. (C). (D) Non-dissociating conditions: associations indicated by arrowheads: mobilities in the second dimension of proteins $\mathrm{CM}$, $\mathrm{CMb}$, and CMd are indicated (a. b. d) at the right side of the figure. IEF was carried out for I extra hour in (D) with respect to (C).

\subsubsection{Noncovalent subunit association in the reserve globulins from Fagaceare}

A different approach to the analysis of noncovalent protein association by 2-D electrophoresis represented by the investigation of the subunit structure of the reserve globulins in Fagaceae. In Fig. 2, the globulin fraction from the Japanese chestnut (Castanea crenata) has been analyzed by a 2-D method combining electrophoresis in a 5-20\% polyacrylamide gradient with SDS-PAGE. The nondissociating conditions of the first separation allow the resolution of oligomers in the 240000-500 000 range, mainly based on their apparent $M_{r}$, whereas under dissociating, but nonreducing conditions prevailing in the second dimension, these oligomers dissociate their noncovalently held subunits. Oligomers made of subunits of uniform size could thus be discriminated from those that are probably constituted by proteins of different sizes, as is the case of the 1IS globulins in Fig. 2, whose structure was confirmed by additional procedures. Similar approaches have been followed in the study of $11 \mathrm{~S}$ globulins from other species, including several Leguminoseae $[26,27]$.

\subsubsection{Investigation of disulfide-linked proteins}

In many seed proteins, subunits differing in size and isoelectric points are linked covalently through disulfide bridges. A general strategy to investigate such associations is outlined for an

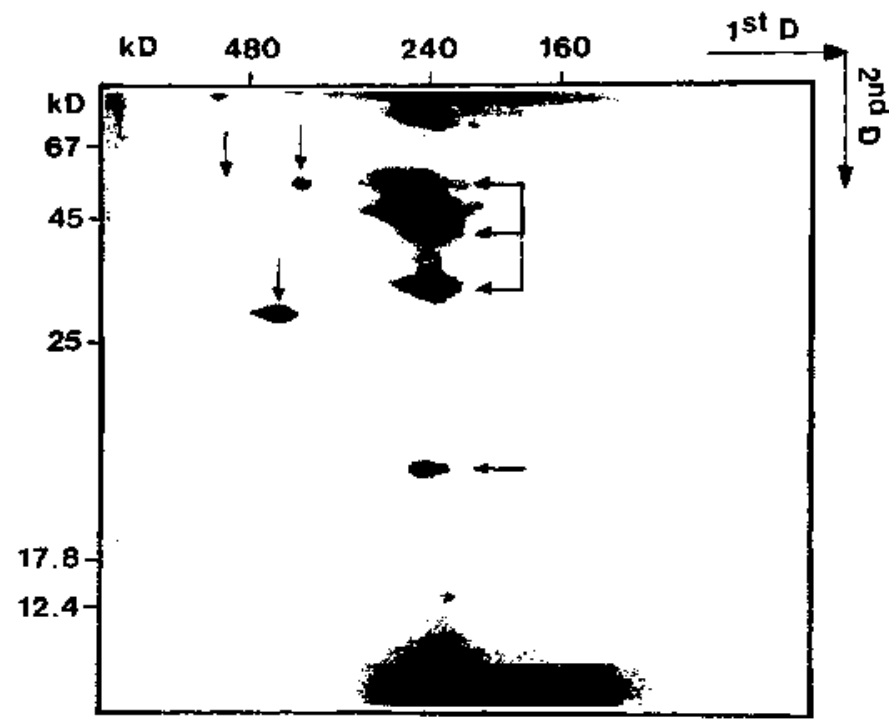

Figure 2. 2-D electrophoresis of C.crenara globulins, extracted with $0.06 \mathrm{M}$ Tris-HCl. pH 6.8. First dimension; pore gradient PAGE (5-20 \% acry)amide). buffer system of Ornstein and Davis $\{16,17\}$. Second dimension: SDS-PAGE without reducing agent in the sample. Subunits of oligomers made of one size-type components are indicated by single arrows. whereas linked arrows point to components of the $11 \mathrm{~S}$ globulins, which are constituted by subunits of different sizes. as confirmed by other methods.

ideal case in Fig. 3A. The following 2-D separations are required: (i) The protein fraction is subjected to SDS-PAGE without reducing agent in the first dimension, followed by SDS-PAGE in presence of a reducing agent in the second dimension. Under these conditions, polypeptides linked by disulfide bridges would appear in vertical lines under the diagonal (Fig. 3A 1). (ii) Fractionation is carried out, in the first dimension, by $\mathrm{IEF}$, under dissociating ( $8 \mathrm{M}$ urea) but nonreducing conditions, followed by SDS-PAGE without reducing agent in the second dimension. This 2-D separation allows the resolution of individual oligomers according to their isoelectric points and apparent $M_{\mathrm{r}}$ (Fig. 3A2). (iii) Fractionation is carried out as in (ii), except that a reducing agent is used in the second dimension. This fractionation avoids overlapping with non-oligomeric components and confirms the results of (i) (Fig. 3A3). (iv) The 2-D separation is performed as in (ii), except that a reducing agent is used in both dimensions. Individual subunits are separated from each other and their apparent $\mathrm{p} \Gamma \mathrm{s}$ can be deduced (Fig. 3A4). A comparison of these with those of the non-dissociated oligomers (Fig. 3A2) completes the information required to identify the different types of oligomers and of subunits integrated in each of them. In the ideal case presented here, three dimers of class $A$

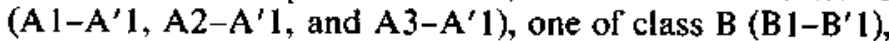
and four of class $C\left(C 1-C^{\prime} 1, C 1-C^{\prime} 2, C 2-C^{\prime} 1\right.$, and $\left.C 2-C^{\prime} 2\right)$ can be identified. In Fig. 3B, the results obtained for an actual case, that of the glutelins of Quercus suber, are presented and the reader may draw his own conclusions. This general strategy has been followed in the characterization of glutelins from other Quercus spp. and of the $11 \mathrm{~S}$ globulins from Castanea and Fagus ([28] and C. Collada et al., unpublished). Similar strategies have been applied to the investigation of 1 is globulins from dicots such as Vicia faba, Pisum sativum and Brassica napus $[26,29,30]$. 


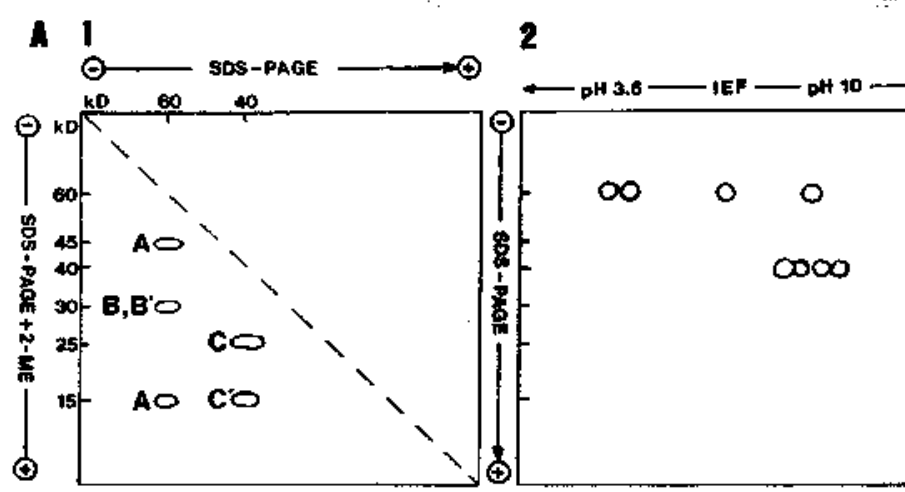

3
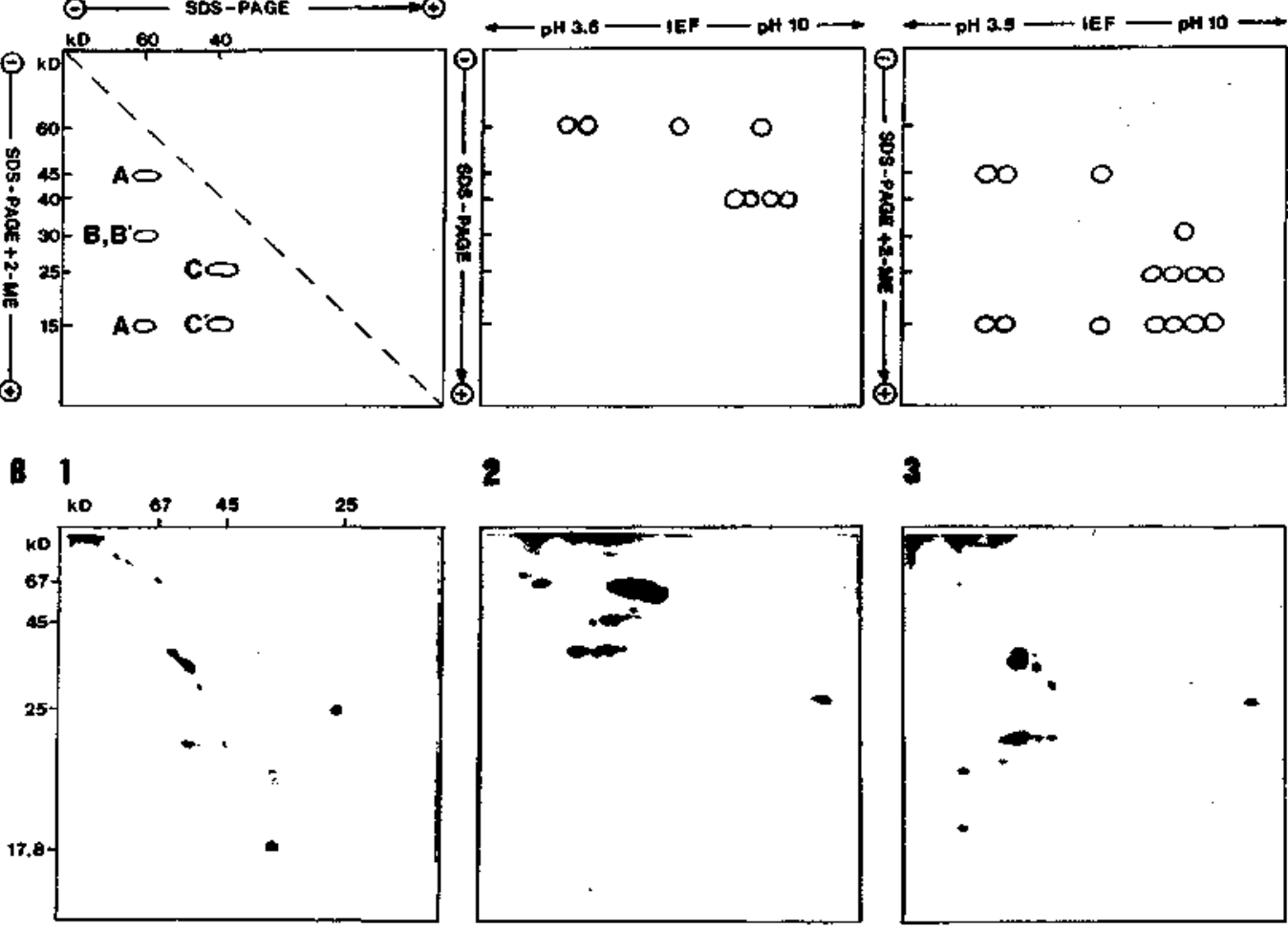

2

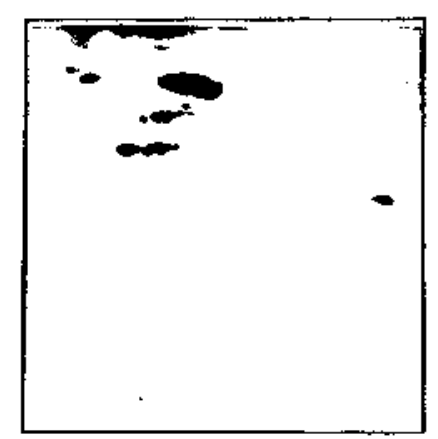

3

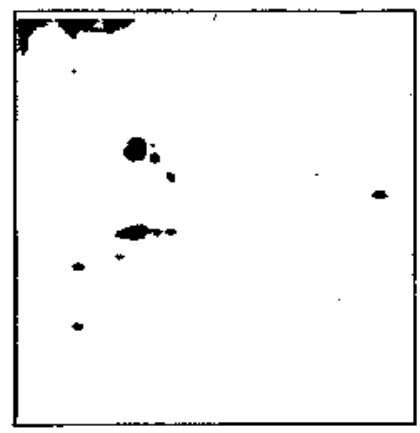

4

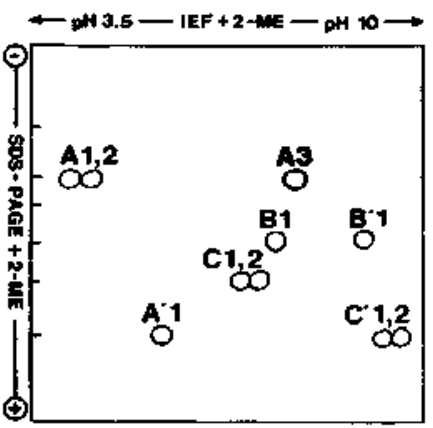

4

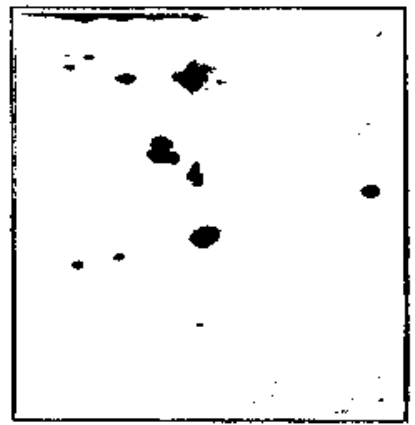

Figure 3. (A) Schematic representation of a general strategy to investigate covalent and non-covalent associations in a hypothetical mixture of seed protein oligomers. (A 1) SDS-PAGE (without 2-ME) $\times$ SDS-PAGE (with 2-ME). (A2) IEF (pH 3.5-10: without 2-ME) $\times$ SDS-PAGE (without 2-ME). (A3) IEF (pH 3.5-10; without 2-ME) $\times$ SDS-PAGE (with 2-ME). (A4) IEF ( $\mathrm{pH} 3.5-10$; with 2-ME) $\times$ SDS-PAGE (with 2-ME). (BI)-(B4) Application of the same separation scheme to the glutelins of $Q$. suber. All IEF separations are in the presence of $8 \mathrm{~m}$ urea.

\subsection{Chromosomal location and homology relationships of genes encoding seed proteins}

\subsubsection{Analysis of genes encoding low molecular weight wheat proteins using aneuploid lines}

Two types of wheat aneuploid series, the compensated nullitetrasomics and the ditelosomics, which have been developed through the pioneering work of E. R. Sears [3 1, 32], have been particularly useful in the investigation of the chromosomal locations of wheat genes. In each of the compensated nullitetrasomic lines, one of the 7 pairs of chromosomes from one of the 3 genomes of hexaploid wheat, Triticum aestivum (AABBDD), is missing and compensated by extra doses of the equivalent (homoeologous) chromosome from one of the other two genomes. In each of the ditelosomic lines, a particular chromosome arm is missing in one of the chromosome pairs. Using this approach, all the nuclear genetic information can be systematically explored. The $2-\mathrm{D}$ technique developed by Wrigley [1], which combined IEF (6 M urea) with SGE (pH 3.2 ), has been applied with various modifications in our laboratory to investigate chromosomal and genomic organization in wheat $[3-6,11,12]$. A representative example of this type of work is summarized in Fig. 4. Three genetic variants of a-amylase inhibitor subunits were purified and characterized by their in vitro activities, amino acid compositions, and $N$-terminal amino acid sequences $[12]$. The genes encoding these inhibitors were assigned to their corresponding chromosomal arms as indicated in Fig. 4: a particular inhibitor was found to be missing in the 2-D map of a nulli-tetrasomic line lacking a particular chromosome and in one of the two ditelosomic lines corresponding to the two arms of that chromosome. An extract of the aneuploids lacking a given inhibitor was suplemented with the appropriate amount of the purified inhibitor to reconstruct the normal (euploid) phenotype and to ascertain its position in the 2-D map (Fig. 4).

\subsubsection{Chromosome assignment of genes controlling salt-soluble proteins in rye}

A genetic map of some wheat-related species can be obtained through the analysis of complete series of disomic addition lines, in which each of the lines carries a pair of chromosomes from the species under study besides the complete genome complement of wheat. In this case, the main problem is a considerable overlapping of the proteins encoded by the alien chromosome over the complex background of the wheat proteins. A 2-D method which combines non-equilibrium IEF with SGE (pH 3.2) has shown the flexibility required for this type of genetic analysis [11]. Varying the time of the first electrophoretic run, which changes the relative positions of the different components in a non-linear manner, allows the identification of the appropriate time-window to resolve a particular component. An example of this approach is presented in Fig. 5, where the location of a number of genes encoding salt-soluble proteins in chromosome $4 \mathbf{R}$ of rye is demonstrated. 


\subsubsection{Genes for the LMWP from wheat}

A
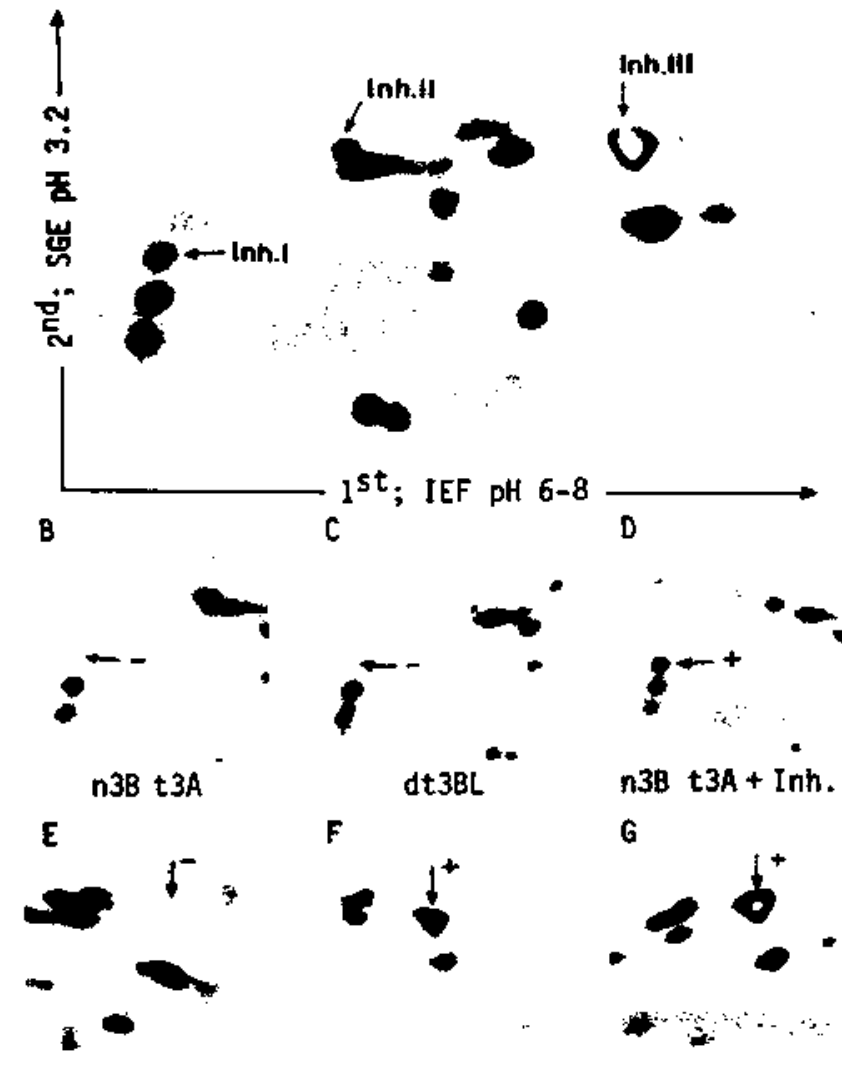

n $3 D$ t $3 A$

H

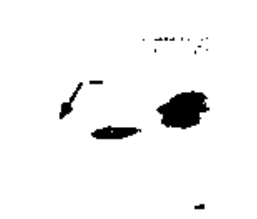

$n 60$ t6B
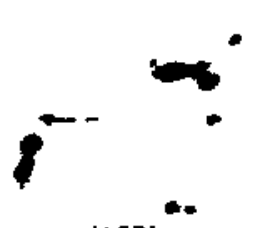

$d+3 B L$

F

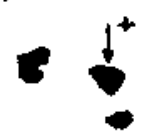

dt30S

I

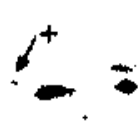

dt6DS

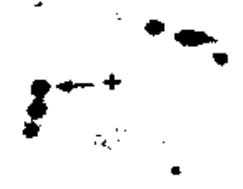

n3B $t 3 A+\operatorname{Inh} . I$

G

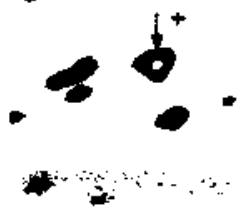

$n 3 D+3 A+I n h$. III

J

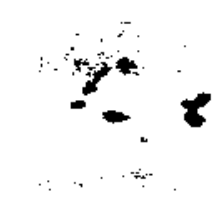

Figure 4. Aneuploid analysis of genes encoding a-amylase inhibitors. Inh. I. Inh. Il and Inh. III of wheat. (A) Separation by combined IEF ( $\mathrm{pH} \mathrm{6-8)}$ $\times$ SGE $(\mathrm{pH} 3.2)$ of a $70 \%$ ethanol extract from $T$. aestivum cv. Chinese Spring. (B)-(J) Pertinent zones of the 2.D maps of the indicated aneuploids. n. nulli: 1. tetra: dt. ditelosomic. Maps (D). (G) and (J) correspond to a mixture of the indicated nulli-tetrasomics and $40 \mu \mathrm{g}$ of purified Inh. I. Inh. III and Inh. II. respectively. A rrows point to the positions of Inh. I-[II: absence and +. presence of the corresponding inhibitor.
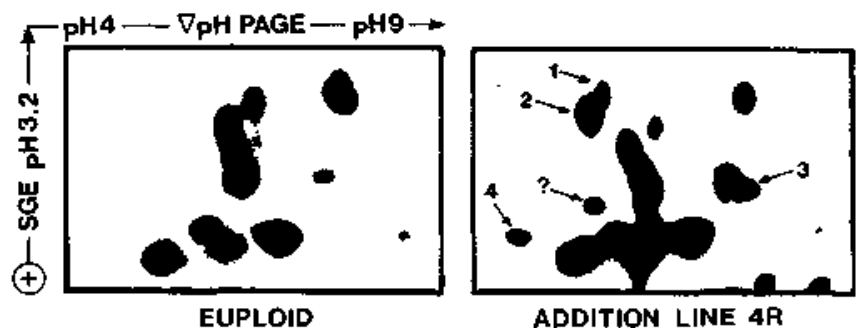

Figure 5. Location of genes encoding salt-soluble proteins from rye in chromosome 4R. Comparison of 2-D maps (non-equilibrium IEF, pH 4-9 $\times$ SGE, pH 3.2) from T. aestium cv. Chinese Spring (euploid) and Chinese Spring wheat/Imperial rye disomic addition line $4 R$. Rye-specific proteins are numbered. The component indicated with a question mark (?) was not detected in wheat or rye. Only the pertinent zone of the 2-D maps is shown.

The genetic analysis of LMWP from wheat, barley and rye was difficult to carry out by any of the methods described above, because this group of homologous proteins had the same solubility properties and electrophoretic mobility at acid $\mathrm{pH}$ as the main reserve prolamins, which were considerably more abundant. A method combining high-concentration PAGE (pH 9) with SGE ( $\mathrm{pH} 3.2$ ) allowed the resolution of these proteins, based on their extremely alkaline $\mathrm{p} \Gamma \mathrm{s}$ and significantly smaller size [8]. The 2-D map of wheat LMWP is shown in Fig. 6 as an example.

\subsubsection{Assignment of purothionin genes in wheat}

Some genetic variants of a given protein are so similar that it is not possible to separate them from each other. This is the case with three purothionins present in wheat endosperm, which could not be separated by PAGE at any of the acrylamide concentrations and $\mathrm{pH}$ conditions tried. However, two purothionin fractions, $\alpha$ and $\beta$, could be separated by combined SGE (pH 5.2) x SGE ( $\mathrm{pH} 3.2$ ) as shown in Fig. 7. This separation permitted a better densitometric estimation of the $\alpha / \beta$ ratios in different aneuploids and the localization of the genes Pur-A1, Pur-BI, and Pur-D1, encoding the $\beta, \alpha 1-$ and $\alpha 2-$ purothionin variants, respectively, in the long arms of chromosomes IA, 1B and ID [4]. Two peculiar features of

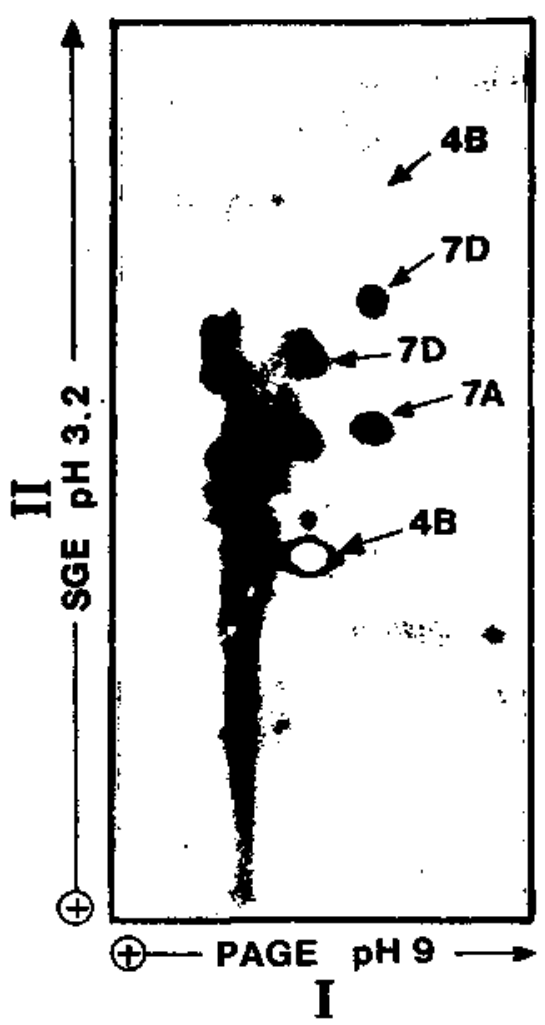

Figure 6. PAGE (pH 9.0) $\times$ SGE (pH 3.2) of LMWP from wheat. Chromosomal locations of genes encoding some of the components are indicated. 


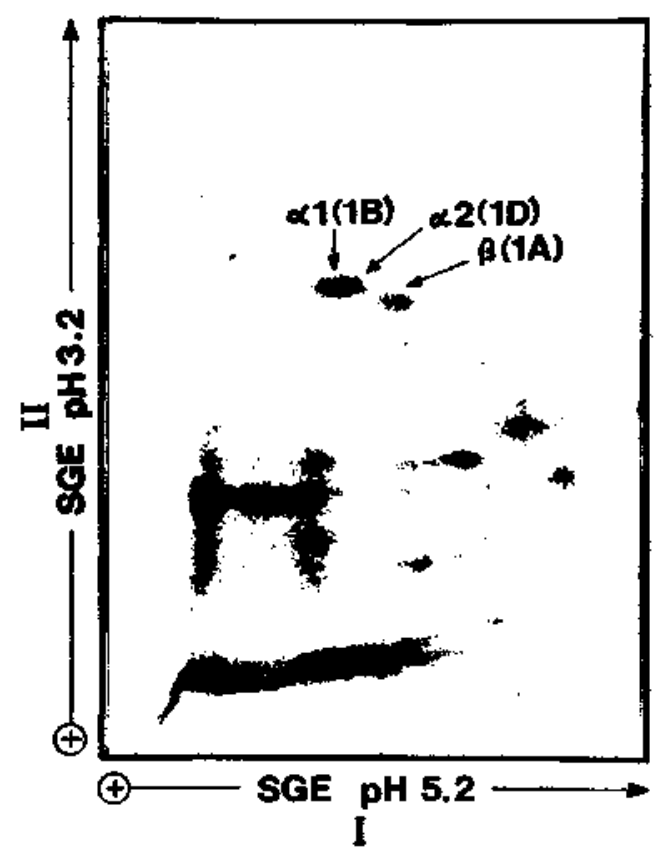

Figure 7. SGE (pH 5.2) $\times$ SGE (pH 3.2) of wheat purothionins. Components and chromosomal locations are indicated.

this 2-D separation are the probable interaction of the proteins with the starch-gel matrix, which would explain why $\alpha$ and $\beta$ types are separated in this gel and not in polyacrylamide gels (up to $20 \%$ ), using the same buffers, and the fact that the migration order of $\alpha$ and $\beta$ is inverted at the two acid pH's used (5.2 and 3.2).

\subsubsection{Preparative 2-D methods}

Important objectives in many of the studies alluded to in this report have been to demonstrate sequence homology between proteins whose structural genes have been assigned to their corresponding chromosomes, and to ascertain in vitro biological activities of the proteins. The required purification of the proteins has often been achieved in our laboratory by preparative 2-D electrophoresis [23, 33]. Because of the superior loading capacity of IEF, as compared with PAGE or SGE, the first separation has usually been carried out on IEF polyacrylamide columns with a diameter of $7 \mathrm{~mm}$ and the second separation on PAGE slabs (pH 3.2) of the same thickness. After electrophoresis, the protein components were visualized by brief immersion of the gel in either $20 \%$ trichloroacetic or ammonium sulfate at $50-70 \%$ saturation. The precipitated proteins were solubilized and eluted from the appropriate gel pieces by placing them in $3 \mathrm{M}$ urea dialysis bags, dialysing against $\mathrm{H}_{2} \mathrm{O}$, and freeze-drying. Amounts ranging from $100 \mu \mathrm{g}$ to $300 \mu \mathrm{g}$ of each pure component could often be obtained, which was enough for amino acid analysis and $N$-terminal sequence determination. As for the in vitro biological activities, the milder ammonium sulfate precipitation gave better results in the case of the enzyme inhibitors studied by us.

\subsection{Gene expression}

The quantitative determination of proteins separated by 2-D electrophoresis, using densitometric techniques has been useful in studies of gene expression and regulation $|4-6|$. In a typical experiment, four 2-D gels of the same extract were run in parallel for each genetic stock to be investigated, the errors of the means being smaller than $7 \%$ for well-resolved components $[5]$. Relative values with respect to other components from the mixture were usually determined, but, when required, absolute values were obtained by estimating the "staining response" of each component through the densitometric determination of appropriate dilution series of known amounts of the purified proteins [6]. Thus differential allelic expression was demonstrated at a locus encoding proteins CM3 and $\mathrm{CM}^{3}$ ' from the tetraploid wheat Triticum turgidum [6]. The net amount of protein molecules was measured for each of the two allelic proteins at one, two and three doses of their corresponding genes. The amount increased linearly with gene dosage for both proteins, but that of $\mathrm{CM}^{\prime}$ was $50-65 \%$ of that found for CM3 at a given gene dosage (Fig. 8). This was detected not only in the parental material and the FI reciprocal hybrids, but also in the segregating $F 2$ generation, indicating that it was a cis regulatory effect $\{6 \mid$. Using similar methods we have also demonstrated trans regulatory effects in hexaploid wheat, where the absence of the gene encoding a given protein in one of the genomes enhanced the amount accumulated of an equivalent protein encoded by one of the other homoeologous chromosomes [5], and in barley, where it

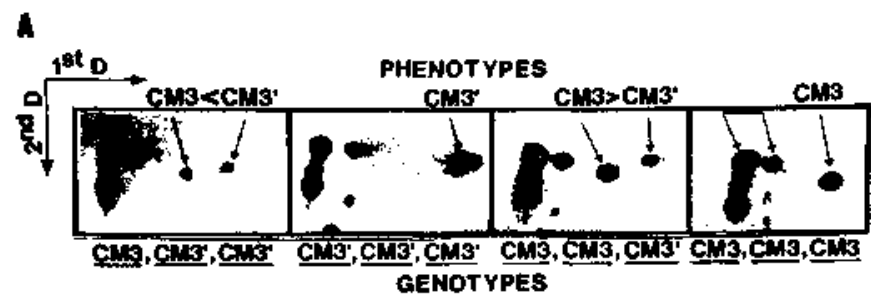

B

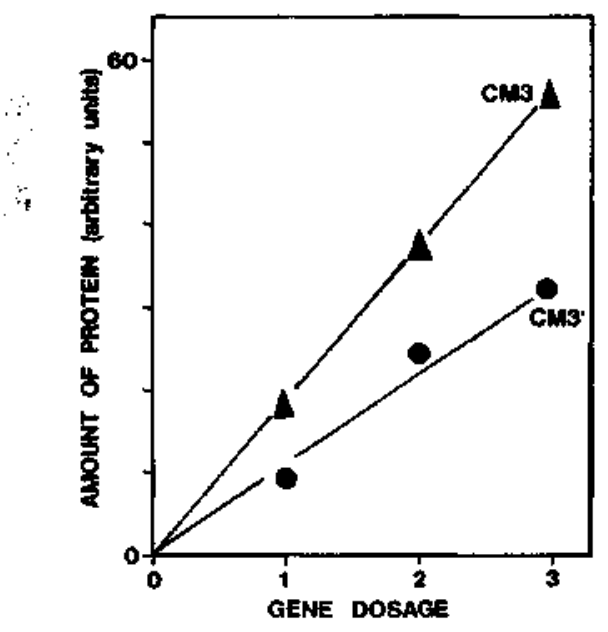

Figture 8. Differential allelic expression at the $\mathrm{Cm} 3 / \mathrm{Cm} 3$ locus in $T$. furgidum. (A) 2-D electrophoresis of stocks with the indicated genotypes and phenotypes (firsi dimension. IEF. pH7-9; second dimension.SGE. pH 3.2). Linked arrows indicate components used to st andardize densitometric measurements in F2 kernels. (B) Net amounts in arbitrary units of proteins $\mathrm{CM} 3$ and $\mathrm{CM} 3^{\prime}$ versis gene dosage. 


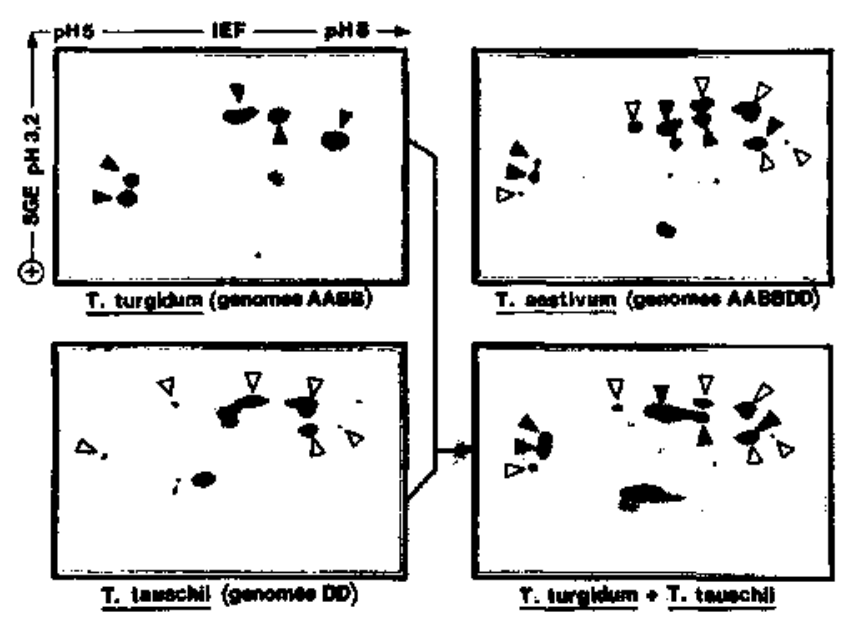

Figure 9. Reconstitution of the allohexaploid $T$, aestirum 2-D map by addition of those of the parental species $T$. turgidum and $T$. tauschii. Full and open arrowheads, respectively. indicate the major proteins contributed by each of the parents. The low-molecular-weight fraction from the $70 \%$ ethanol extracts were fractionated.

was shown that the gene encoding trypsin inhibitor $\mathrm{CMe}$, located in chromosome 3 , is switched off by a "high-lysine" mutation affecting a regulatory locus in chromosome $7[10$, 34 l.

\subsection{Phylogenetic, evolutionary and identification studies}

\subsubsection{Genome donors of alloploid species}

A high proportion of plant genera include spieces of recognizable alloploid origin and possibly over one third of all plant species, including many cultivated ones, are either obvious or cryptic alloploids. Analysis by 2-D electrophoresis of appropriate groups of proteins showing low intra-specific variability is an eflicient method of identification of the genome donors of a particular alloploid. An example of this approach is shown in Fig. 9, where reconstruction of the hex. aploid wheat $2-D$ protein map has been carried out mixing protein extracts from the putative parental species.

\subsubsection{Morocco as a possible domestication center for barley}

Cereal proteins that are soluble in chloroform/methanol mixtures (CM proteins) include trypsin inhibitors and subunits from oligomeric inhibitors of heterologous $\alpha$-amylases which present an extremely low intraspecific variability, as judged by 2-D electrophoresis [10,35]. Rare allelic variants of these proteins have proved to be quite useful in an investigation of a possible domestication center for barley in Morocco [10,13]. An extensive survey of CM protein 2-D maps from Hordeum vulgare cultivars and $H$. spontaneum accessions was carried out, and the allelic relationships of the observed variants was

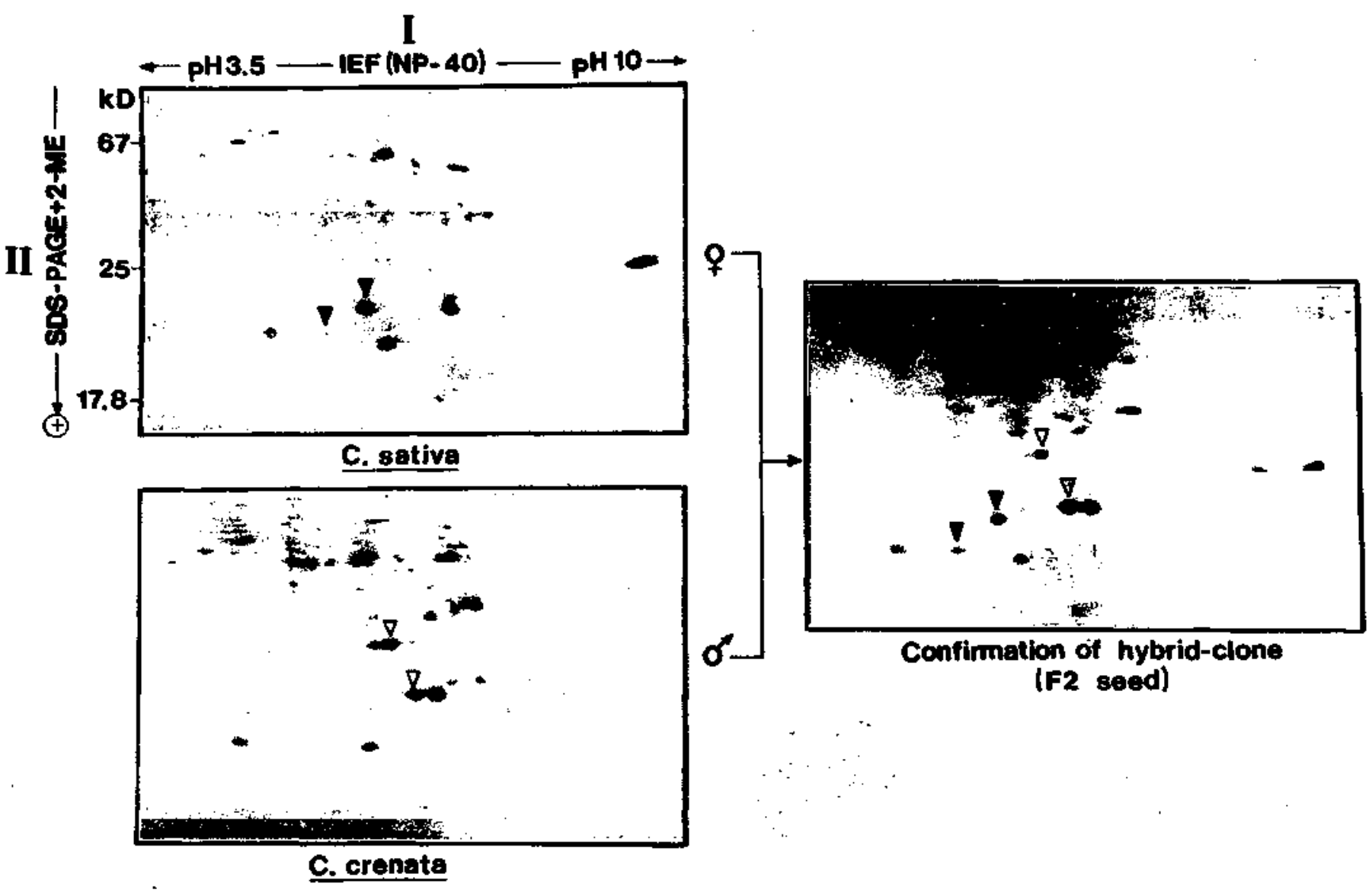

Figure 10. Confirmation of a hybrid clone of C. satira $\times$ C. crenara. Total proteins extracted from individual seeds with Tris-HCl.pH 6.8.0.5\% SDS. $8 \mathrm{~m}$ urea. 3 \% 2-ME. were fractionated as indicated. Protein markers from $C$. sativa (full arrow heads) and $C$. crenata (open arrow heads) were used in the identification of the hybrid. 
established through the 2-D electrophoretic analysis of individual kernels from the appropriate $F 2$ generations. The fact that certain rare variants were restricted to both cultivated and wild barley from Morocco suggested this site as one of the domestication centers of this crop [13].

\subsubsection{Application of 2-D electrophoresis to identification problems in tree breeding}

Identification problems, which are ubiquitous in plant genetics, are especially relevant in the practical manipulation of forest trees because of their long generation times and of the importance of vegetative propagation in tree breeding. The following are some of the applications of 2-D electrophoresis in this context: (i) identification of clones. (ii) identification of provenance, (iii) early confirmation of hybrids and grafts, (iv) pollination control in seed orchards (presence of alien pollen, incompatibility among clones, etc.), and (v) determination of the effectiveness of supplemental mass pollination, etc. An example of one such application, the confirmation of a hybrid, is presented in Fig. 10.

\section{Concluding remarks}

\subsection{2-D electrophoresis - a versatile tool}

The variety of 2-D electrophoretic procedures described here shows the flexibility of this separation method as a high resolution tool that can be used not only on a qualitative basis but also for quantitative and preparative purposes. In many cases, such as certain structural studies, they represent a considerable saving of time and expense over alternative procedures. Their high sensitivity allows the analysis of the biochemical phenotype of an individual (seed or small plant) without destroying its capacity to produce progeny, which is ideal for genetic studies. The choice of separation procedure is dictated by the problem at hand and no general recommendations can be made. However, it can be pointed out that SDSPAGE is more useful for structural studies, where apparent $M_{r}^{\prime}$ 's are of interest, than in genetic studies, where groups of proteins of the same size have to be separated from each others. In the latter case, a combination of two separation methods based on charge properties of the molecules at two different situations (i.e. IEF, non-equilibrium IEF, acid or alkaline $\mathrm{pH}$, presence or absence of dissociating and/or reducing agent, etc.) usually gives a better resolution.

\subsection{Wide range of problems}

The examples that have been succinctly presented here are but a sampling of the variety of basic and applied problems in plant biology that can be solved by 2-D electrophoresis. Other applications would have equally deserved to be highlighted, as, for example, the use of biochemical markers in the interspecific transfer of genes, in the manipulation of disease resistance genes, and in the characterization of recombinant chromosomes carrying alien genetic material [36-38]. The use of specific proteins in the identification of plant ingredients in manufactured food products, or, at a more basic level, the use of 2-D maps to follow early events in the plant response to both environmental stress (heat, cold, anaerobiosis, etc.) and exogenously applied hormones are also relevant examples.
Financial support from the Comision Asesora de Investigacion Cientifica y Tecnica (grants No. 2049/83 and No. 12/87) and technical assistance from R. Casado, L. Lamoneda andJ. Garcia are gratefully acknowledged.

Received June 4, 1988

\section{References}

[1] Wrigley, C. W., Biochem. Genet, 1970, 4, 509-516.

12| O'Farrell. P. H., J. Biol. Chem. 1975, 250,4007-4021.

[3] Aragoncillo, C., Rodriguez-Loperena, M. A.. Carbonero,P. and Garcia-Olmedo, F., Theor. Appl. Genet. 1975, 45, 322-326.

[4] Fernandez de Caleya, R.. Hernandez-Lucas, C.. Carbonero. P. and Garcia-Olmedo, F., Genetics 1976, 83, 687-699.

[5| Aragoncillo, C., Rodriguez-Loperena, M. A., Salcedo, G., Carbonero, P. and Garcia-Olmedo, F., Proc. Natl. Acad. Sci. USA 1978, $75,1446-1450$.

[6] Salcedo, G., Aragoncillo, C., Rodriguez-Loperena, M. A., Carbonero, P. and Garcia-Olmedo, F.. Genetics 1978, 89, 147-156.

[7] Sanchez-Monge, R., Delibes, A., Hernandez-Lucas, C., Carbonero, P. and Garcia-Olmedo, F, Theor. Appl. Genet. 1979, 54,6I-63.

[8] Salcedo, G., Prada, J., Sanchez-Monge, R. and Aragoncillo, C., Theor. Appl. Genet. 1980, 56, 65-69.

(9) Garcia-Olmedo, F., Carbonero. P. and Jones, B. L., Adv. Cereal Sci. Technol. 1982. S, 1-47.

[ 10 ] Salcedo, G., Fra-Mon. P., Molina-Cano. J. L., Aragoncillo. C. and Garcia-Olmedo, F., Theor. Appl. Genet. 1984, 68,53-59.

[11] Fra-Mon, P.. Salcedo, G.. Aragoncillo, C. and Garcia-Olmedo, F.. Thear. Appl. Genes. 1984. 69, 167-172.

「121 Sanchez-Monge. R., Barber, D., Mendez. E.., Garcia-Olmedo, F. and Salcedo, G., Theor, Appl. Genet, 1986, 72, 108-113.

\{13] Molina-Cano, J. L., Fra-Mon, P., Salcedo, G.. Aragoncillo, C., Roca de Togores, F. and Garcia-Olmedo, F., Theor. Appl. Genet. 1987, 73, $531-536$.

[14] Sanchez-Monge, R., Fernandez, J. A. and Salcedo, G., Theor. Appl. Genet. 1987, 74, 811-816.

[15] Gomez. L., Sanchez-Monge, R, and Salcedo, G., Theor. Appl. Genet. $1988,75,674-678$.

[16] Ornstein. L., Ann. N. Y. Acad. Sci. 1964, 121, 321-349.

[17] Davis, B. J., Ann. N. Y. Acad. Sci. 1964, 12I, 404-427.

[18] Laemmli, U. K, Nature 1970, 227, 680-685.

[19] Aragoncillo, C.. Rodriguez-Loperena, M. A.. Carbonero, P. and Garcia-Olmedo, F., Anal. Biochem. 1975, 63, 603-606.

|20| Blakesley, R. W. and Boezi, J. A., Anal. Biochem. 1977,82, 580-582.

12II Petrucci, T., Tomasi, M., Cantagalli, P. and Silano, V., Phytochemistry 1974, 13, 2487-2495.

\{22\} Garcia-Olmedo, F.. Salcedo, G., Sanchez-Monge, R., Gomez, L.. Royo. J. and Carbonero, P., in: Millin. B. J. (Ed.). Oxford Surveys of Plant Molecular and Cell Biology'. Vol. 4, Oxford University Press, New York 1987. pp. 275-334

[23] Salcedo, G., Sanchez-Monge, R. and Aragoncillo, C., J. Exp. Bot. 1982, 33, 1325-1331.

[24] Barber, D.. Sanchez-Monge, R., Mendez, E., Lazaro, A.. GarciaOlmedo, F. and Salcedo, G. Blochim. Biophys. Acta 1986. 869. 115-118.

[25] Sanchez-Monge, R.. Gomez, L.. Garcia-Olmedo, F. and Salcedo, G., FEBS Lell. 1986, 207, 105-109.

(26) Matta, N. K., Gatehouse, J. A. and Boulter, D., J. Exp. Bot. 1981, 32, 183-197.

[27] Dalgalarrondo, M., Raymond, J. and Azanza.J. L...J. Exp. Bot. 1984, 35, 1618-1628.

(28) Collada, C., Casado, R., Barber, D., Fernandez de Caleya, R. and Aragoncillo, C., J. Exp. Bot. 1986, 37, 1872-1878.

[29] Matta. N. K., Gatehouse, J. A. and Boulter, D., J. Exp. Bot, 1981,32, 1295-1307.

[30] Dalgalarrondo, M., Robin, J. M. and Azanza. J. L.. Plant Sci. 1986. 43, 115-124.

[31] Sears, E. R., Mo. Agric. Exp. Sin. Res. Bull. 1954, 572, 1-58.

[32] Sears, E. R., Hereditas, Suppl. 1966, 2, 370-38I. 
[33] Prada, J.,Sanchez-Monge, R., Salcedo, G. and Aragoncillo, C., Plant Sci. Lett., 1982, 25, 281-289.

[34] Lazaro, A., Barber, D., Salcedo, G., Mendez, E. and Garcia-Olmedo, F., Eur. J. Biochem. 1985, 149, 617-623.

[35] Rodriguez-Loperena, M. A., Aragoncillo, C., Carbonero, P. and Garcia-Olmedo, F., Phytochemistry 1975, 14, 1219-1223.
[36] Rodriguez-Loperena, M. A., Aragoncillo, C., Torres, J. V.. Carbonero, P. and Garcia-Olmedo, F., Plant Sei.Lett. 1975, 5,387-393.

[37] Delibes, A., Dosba, F., Otero, C. and Garcia-Olmedo, F., Theor. Appl. Genet. 1981, 60, 5-10.

[38] Doussinault. G., Delibes, A., Sanchez-Monge, R. and GarciaOlmedo, F., Nature 1983, 303, 698-700. 